\title{
Asthma and hypertension; a pilot study
}

\author{
Parsa Yousefichaijan ${ }^{1}$, Sima Zahedi ${ }^{*}$, Habib Soheili ${ }^{3}$, Mohammad Rafiei ${ }^{4}$ \\ ${ }^{1}$ Department of Pediatric Nephrology, Arak University of Medical Sciences, Arak, Iran \\ ${ }^{2}$ Students Research Committee, Arak University of Medical Sciences, Arak, Iran \\ ${ }^{3}$ Department of Pediatric Allergy and Immunology, Arak University of Medical Sciences, Arak, Iran \\ ${ }^{4}$ Department of Biostatistics and Epidemiology, School of Medicine, Arak University of Medical Sciences, Arak, Iran
}

\section{AR T I C L E I N F O}

\section{Article Type:}

Original

\section{Article History:}

Received: 22 June 2017

Accepted: 30 August 2017

Published online: 11 September 2017

\section{Keywords:}

Asthma

Hypertension percentile

Children

\section{A B S T R A C T}

Introduction: Asthma is a medical condition characterized by narrowing the airways, swelling and deposition of extra mucus in the airways. This condition leads to difficulty in breathing and causes coughing, wheezing and shortness of breath.

Objectives: This study attempted to find a probable link between asthma and hypertension. Patients and Methods: This is a case-control study which evaluated 100 asthma patients with 100 healthy children by comparison. The relationship between asthma and hypertension was analyzed using the SPSS software, version 18.00. The application of Student's t-test and chisquare test was based on whether the data is continuous or not.

Results: It was found that the risk of hypertension in children is affected and increased by asthma.

Conclusion: This study showed that asthma has a significant effect on the occurrence of hypertension.
\end{abstract}

Implication for health policy/practice/research/medical education:

This study investigated the existence of a possible link between asthma and hypertension, hypothesizing that asthma could increase the risk of hypertension and determine whether the adjustment of asthma could decrease the frequency of hypertension. Please cite this paper as: Yousefichaijan P, Zahedi S, Soheili H, Rafiei M. Asthma and hypertension; a pilot study. J Renal Inj Prev. 2018;7(3):197-200. doi: 10.15171/jrip.2018.46.

\section{Introduction}

Airway inflammation has appeared as an important contributor to the mechanisms of asthma that can cause narrowing the airways. This inflammation is important in the later and more persistent development of bronchial obstruction (1-3). Patients with asthma have bouts of breathlessness, chest tightness, coughing and wheezing that are due to generalized airway obstruction (2-5).

Generalized airway obstruction in asthma causes the patient to experience dyspnea, chest discomfort, coughing and wheezing.

Approximately 300 million people of all age groups and all cultural backgrounds suffer from asthma, including 6.5 million patients in the United States who are children and the financial cost, mortality and morbidity to authority, health systems, families and patients is increasing globally $(1,6)$. More than $5 \%$ of the community members are affected with asthma, and researchers have predicted that its frequency is still increasing, especially among children. The burden of this disease has continued to increase, despite the new developments in its recognition and management (7). The most usual presentation of childhood respiratory tract illnesses is wheezing. This symptom plays an important role not only because it contributes to acute morbidity but also because a high risk for asthma is indicated by childhood wheezing (8).

When lung mononuclear cells have been activated, they produce pro-inflammatory cytokines including the eosinophils and mast cells $(2,9)$. Both variants are distinguished by tissue infiltration by eosinophils and activated $\mathrm{T}$ cells as well as the increased biosynthesis of interleukin-4, interleukin-5, interleukin-13, and chemokines (10). It has been shown that cytokines are important mediators of bronchoconstriction in asthma. Additionally, leukotrienes are the strong proinflammatory cytokines found in high concentrations in asthmatic bronchioles. Both of them also interact in atherosclerotic plaques. Hence, inflammation is 
associated with several comorbidities and ingredients in asthma. Inflammation also contributes to left ventricular hypertrophy and possibly right ventricular hypertrophy. Inflammation in asthmatic patients may also contribute to hypertension (10-15).

\section{Objectives}

Considering the rates of verified hypertension $(>3 \%)$ and pre-hypertension ( $>3 \%)$ in children and adolescents, who have no symptoms, high blood pressure should be considered a common long-term health obstacle in childhood (16,17). An attempt has therefore been made to conduct a study on the possible relationship between asthma and hypertension.

\section{Patients and Methods \\ Study population}

In this case-control study, 100 asthma patients were compared with 100 healthy children. This case-control study was performed on 200 children in the age group of more than 5 years, referred to the pediatric clinic of the Amir Kabir hospital in Arak, Iran. Of the 200 children under study, 100 children with asthma served as the case group and 100 healthy children without asthma served as the control group and were included in the study based on the inclusion and exclusion criteria.

Our inclusion criteria were; 1) children of both genders above five years of age, 2) children with asthma according to its diagnostic criteria and 3) written consent from patients' parents or guardians. Our exclusion criteria were; 1) congenital and chromosomal abnormalities, 2) history of considerable or chronic medical disorders, 3) chronic medication use, 4) patients with non-cooperativie parents or guardians, and 5) the presence of any active or chronic infections.

\section{Ethical issues}

The research followed the tenets of the Declaration of Helsinki. Informed consent was obtained and the research was approved by the ethical committee of Arak University of Medical Sciences, Iran.

\section{Statistical analysis}

To investigate the relationship between asthma and hypertension, results analysis was performed using SPSS software, version 18.00. Student's $t$ test and chi-square test were applied based on whether the data is continuous or not. Statistical significance was evaluated at $P<0.05$ $(18,20)$.

In order to divide children based on blood pressure percentile, there are four groups of blood pressure percentile based on sex, weight and height; 1) Blood pressure percentile $<90$ th means normal. 2) Blood pressure percentile between 90th-95th means prehypertension. 3) Blood pressure percentile between 95th-99th $+5 \mathrm{~mm} \mathrm{Hg}$ means hypertension stage 1. 4) Blood pressure percentile >99th +5 mm Hg means hypertension stage 2 (19).

\section{Results}

Asthmatic children had a mean age of $6.9 \pm 1.9$ years (age at the time of diagnosis). The control group had a mean age of $7 \pm 2.3$ years. There was no predominance of one gender among the two groups. Around $41 \%$ of the cases population were girls and $53 \%$ of the control population were girls. Around, 59\% of cases population were boys while $47 \%$ of the control population were boys ( $P=$ 0.119 ). In this study, normal blood pressure percentile was found in 83 cases and 82 controls. Around 6 cases and 2 controls were in the 90th-95th blood pressure percentile. Moreover, 11 cases and 6 subjects in the control group had 95th-99th $+5 \mathrm{~mm} \mathrm{Hg}$ blood pressure percentile. None of the cases had more than 99th $+5 \mathrm{~mm} \mathrm{Hg}$; however 10 control subjects had more than 99th $+5 \mathrm{~mm} \mathrm{Hg}$ blood pressure percentile $(P=0.004$, Table 1$)$.

\section{Discussion}

Based on our study, a significant difference between asthma and hypertension was detected. At present, there are insufficient studies over the relation between asthma and hypertension in children. Based on the previous works of Salako and Ajayi, a significant relationship of asthma and hypertension was detected. The mean age of the group with acute severe asthma was $30 \pm 9.9$ years and the mean age of the group with stable asthmatic patients was $45 \pm 15$ years. They concluded that the frequency of high blood pressure among asthmatics is utterly high. It was also found that a concurrent family history of hypertension and the frequency of attack of acute severe asthma did not seem to designate the status of blood pressure (21).

Based on an earlier study, Steinmann et al found that arterial stiffness increased in children with mild and moderate asthma (22). Brachial-ankle pulse wave velocity tends to increase as the pathogenic condition aggravated in asthma (23).

Twenty-four hours monitoring of blood pressure in groups of patients of elderly age with bronchial asthma and hypertension was administered. The study showed an increased variability of blood pressure and its inadequate reduction at night time resulted in the development of cardiovascular complications (24). Recent studies have

Table 1. The comparison of gender and blood pressure percentile between children above 5 years of age with and without asthma

\begin{tabular}{lllll}
\hline Factors & & $\begin{array}{l}\text { Case } \\
\text { No. }(\%)\end{array}$ & $\begin{array}{l}\text { Control } \\
\text { No. (\%) }\end{array}$ & P value \\
\hline \multirow{2}{*}{ Gender } & Female & $41(41)$ & $53(53)$ & \multirow{2}{*}{0.119} \\
& Male & $59(59)$ & $47(47)$ & \\
Blood pressure & $90<\mathrm{BP}<95^{\text {th }}$ & $6(6)$ & $2(2)$ & \multirow{2}{*}{0.004} \\
Percentile & $95<\mathrm{BP}<99+5^{\text {th }}$ & $11(11)$ & $6(6)$ & \\
& $\mathrm{BP}>99+5^{\text {th }}$ & $0(0)$ & $10(10)$ & \\
\hline
\end{tabular}


shown that in respect to the relationship between the composition of particulate matter and blood pressure at age 12, exposure to particulate material constituents, especially iron, could increase blood pressure in children. The likely connection between the health relevance of nonexhaust emissions of traffic with iron can be distinguished (25). It is also possible that persistent chronic asthma increases the risk of chronic kidney disease or aggravates it, while chronic asthma aggravates hypertension (26). If left untreated, idiopathic pulmonary arterial hypertension (an uncommon disorder) can result to right heart failure. Most patients with idiopathic pulmonary arterial hypertension present dyspnea with exertion, as often seen in asthma (27).

\section{Conclusion}

Unfortunately, there are few evidences on the relationship between asthma and hypertension. Hopefully, the findings of the present study will motivate the performance of more comprehensive studies to determine the relationship between asthma and hypertension with the aim of studying the pathophysiology due to better management of asthma and to evaluate if the adjustment of this condition can control the frequency of hypertension. The reason behind the few nuances between some of the results presented in this study with other researches is due to the limited population study. Furthermore, in this approach, stress was put upon hypertension 99th $+5 \mathrm{~mm} \mathrm{Hg}$ blood pressure percentile $(P=0.004)$.

\section{Study limitations}

The most obvious limitation of this study is the small number of patients who participated in the study. Multicentric studies on this area of allergic diseases, such as asthma, are suggested.

\section{Authors' contribution}

PY participated in the study arrangement, data collection and is the lead author of the article. Some parts of the manuscript were written by MR. SZ and HS participated in the arrangement of the study, performed statistical analysis and finalized the manuscript. All authors read and approved the final manuscript.

\section{Conflicts of interest}

There are no conflicts of interest.

\section{Ethical considerations}

The authors fully observed and complied with ethical issues such as plagiarism, data fabrication, and double publication.

\section{Funding/Support}

The authors gratefully acknowledge the Research Council of Arak University of Medical Sciences (Grant \# 2235) for the financial assistance.

\section{References}

1. Milligan KL, Matsui E, Sharma H. Asthma in urban children: epidemiology, environmental risk factors, and the public health domain. Curr Allergy Asthma Rep. 2016;16:33. doi: 10.1007/s11882-016-0609-6.

2. Busse WW, Coffman RL, Gelfand EW, Kay AB, Rosenwasser LJ. Mechanisms of persistent airway inflammation in asthma. A role for $\mathrm{T}$ cells and T-cell products. Am J Respir Crit Care Med. 1995;152:388-93. doi: 10.1164/ ajrccm.152.1.7599853.

3. Bardal S, Smith A, Luo HA, Zhang T, Groeneweg G, Jimenez Mendez R, et al. Asthma in British Columbia: are we finally breathing easier? A population-based study of the burden of disease over 14 years. J Asthma. 2017;54:308-17. doi: 10.1080/02770903.2016.1208223.

4. Ozoh O, Bandele E. A synopsis of asthma research in Nigeria between 1970 and 2010. African J Res Med. 2012;7:5-11.

5. Postma DS, Rabe KF. The Asthma-COPD Overlap Syndrome. N Engl J Med. 2015;373:1241-9. doi: 10.1056/ NEJMra1411863.

6. Masoli M, Fabian D, Holt S, Beasley R. The global burden of asthma: executive summary of the GINA Dissemination Committee report. Allergy. 2004;59:469-78. doi: 10.1111/j.1398-9995.2004.00526.x.

7. Nathan RA, Sorkness CA, Kosinski M, Schatz M, Li JT, Marcus P, et al. Development of the asthma control test: a survey for assessing asthma control. J Allergy Clin Immunol. 2004;113:59-65. doi: 10.1016/j.jaci.2003.09.008.

8. Alper Z, Sapan N, Ercan I, Canitez Y, Bilgel N. Risk factors for wheezing in primary school children in Bursa, Turkey. Am J Rhinol. 2006;20:53-63.

9. Liu CL, Zhang JY, Shi GP. Interaction between allergic asthma and atherosclerosis. Translational research. J Lab Clin Med. 2016;174:5-22. doi: 10.1016/j.trsl.2015;174:5-22.

10. Li L, Xia Y, Nguyen A, Lai YH, Feng L, Mosmann TR, et al. Effects of Th2 cytokines on chemokine expression in the lung: IL-13 potently induces eotaxin expression by airway epithelial cells. J Immunol. 1999;162:2477-87.

11. Expert Panel Report 3 (EPR-3): Guidelines for the Diagnosis and Management of Asthma-Summary Report 2007. J Allergy Clin Immunol. 2007;120:S94-138. doi: 10.1016/j. jaci.2007.09.043.

12. Gullotta TP, Ma M, Gullotta TP, Blau GM. Handbook of childhood behavioral issues: Evidence-based approaches to prevention and treatment: Routledge; 2007.

13. Ura M, Tanaka H, Takahashi K, Yamazaki H, Fujimoto K. [Value of fractional exhaled nitric oxide after using a beta2 bronchodilator in the differential diagnosis of bronchial asthma and chronic obstructive pulmonary disease]. Rinsho Byori. 2016;64:127-32.

14. Falkner B, Daniels SR. Summary of the fourth report on the diagnosis, evaluation, and treatment of high blood pressure in children and adolescents. Hypertension. 2004;44:387-8. doi: 10.1161/01.HYP.0000143545.54637.af

15. Rodriguez-Saldana J, Rodriguez-Flores M, Cantu-Brito C, Aguirre-Garcia J. A pathological study of the epidemiology of atherosclerosis in Mexico City. Cardiol Res Pract. 2014;2014:264205. doi: 10.1155/2014/264205

16. Falkner B. Hypertension in children and adolescents: epidemiology and natural history. Pediatr Nephrol. 2010;25:1219-24. doi: 10.1007/s00467-009-1200-3.

17. Flynn JT, Tullus K. Severe hypertension in children and 
adolescents: pathophysiology and treatment. Pediatr Nephrol. 2009;24:1101-12. doi: 10.1007/s00467-008-10001.

18. Sha L, Shao M, Liu C, Li S, Li Z, Luo Y, et al. [The prevalence of asthma in children: a comparison between the year of 2010 and 2000 in urban China]. Zhonghua Jie $\mathrm{He} \mathrm{He} \mathrm{Hu} \mathrm{Xi}$ Za Zhi. 2015; 38:664-8.

19. Bartosh SM, Aronson AJ. Childhood hypertension. An update on etiology, diagnosis, and treatment. Pediatr Clin North Am. 1999;46:235-52.

20. Lezana V, Gajardo A, Bofill L, Gutierrez M, Mora S, Castro-Rodriguez JA. Airway tone dysfunction among pre-schoolers with positive asthma predictive index: A case-control study. Allergol Immunopathol (Madr). 2017;45:169-74. doi: 10.1016/j.aller.2016.05.006.

21. Salako BL, Ajayi SO. Bronchial asthma: a risk factor for hypertension? Afr J Med Med Sci. 2000;29:47-50.

22. Steinmann M, Abbas C, Singer F, Casaulta C, Regamey N, Haffner D, et al. Arterial stiffness is increased in asthmatic children. Eur J Pediatr. 2015;174:519-23. doi: 10.1007/ s00431-014-2423-2.

23. Sun WX, Jin D, Li Y, Wang RT. Increased arterial stiffness in stable and severe asthma. Respir Med. 2014;108:57-62. doi: 10.1016/j.rmed.2013.10.021.

24. Orakova FH, Inarokova AM, Ramazanova KA, Semenova IL. Dynamics of twenty-four hour monitoring of blood pressure in elderly patients with bronchial asthma. Adv Gerontol. 2015;28:326-8.

25. Bilenko N, Brunekreef B, Beelen R, Eeftens M, de Hoogh K, Hoek G, et al. Associations between particulate matter composition and childhood blood pressure--The PIAMA study. Environ Int. 2015;84:1-6. doi: 10.1016/j. envint.2015.07.010.

26. Liu DW, Zhen XG, Liang Y, Jing XG, Zhang TS, Zhang GJ, et al. Persistent asthma increases the risk of chronic kidney disease: a retrospective cohort study of 2354 patients with asthma. Chin Med J (Engl). 2013;126:4093-9.

27. Hayes D Jr. Idiopathic pulmonary arterial hypertension misdiagnosed as asthma. J Asthma. 2007;44:19-22. doi: $10.1080 / 02770900601125243$.

Copyright $\odot 2018$ The Author(s); Published by Nickan Research Institute. This is an open-access article distributed under the terms of the Creative Commons Attribution License (http://creativecommons.org/licenses/by/4.0), which permits unrestricted use, distribution, and reproduction in any medium, provided the original work is properly cited. 